\title{
Pengaruh Motivasi dan Kecemasan Belajar Matematika Terhadap Kesadaran Metakognisi dan Kaitannya dengan Hasil Belajar Matematika
}

\author{
Manggala Wihasta Jagat Wicaksana ${ }^{1^{*}}$, Baidowi ${ }^{2}$, Eka \\ Kurniawan', Muhammad Turmuzi ${ }^{2}$ \\ ${ }^{1}$ Mahasiswa Pendidikan Matematika, Universitas Mataram, Mataram, Indonesia \\ ${ }^{2}$ Pendidikan Matematika, Universitas Mataram, Mataram, Indonesia
}

*Corresponding Author e-mail: manggala.wihasta@gmail.com

Received: 25-03-2021; Revised: 25-03-2021; Published: 25-03-2021

\begin{abstract}
This study aims to find out the effect of motivation, anxiety of mathematic's learning and metacognition awareness to students' mathematic's learning outcomes of class XI IPA SMA Negeri 1 Kuripan academic year 2019/2020. The type of this research were quasi-experimental. Determination of the sample used saturation sampling by selected the entire population as a sample, namely class XI IPA. The instrument were questionnaire of motivation, anxiety and metacognition awareness were first tested for validity and reliability in class XII IPA 1 and XII IPA 2. Before a simple linear regression analysis and t-test were performed, the data that had been obtained were first subjected to a prerequisite test. A prerequisite test was normality, homogenity and linearity tests. Based on the results of data analysis used inferential statistical techniques, it can be concluded that, there was a positive effects of mathematic's learning motivation to metacognition awareness, mathematic's learning motivation to students' mathematic's learning outcomes, metacognition awareness to student mathematic's learning outcomes, and there was negative effects $(r=-0.065)$ of mathematic's learning anxiety to students' mathematic's learning outcomes.
\end{abstract}

Keywords: Motivation; Anxiety; Metacognition Awareness; Student Mathematics Learning Outcomes

\begin{abstract}
Abstrak
Penelitian ini bertujuan untuk mengetahui pengaruh motivasi, kecemasan belajar matematika dan kesadaran metakognisi terhadap hasil belajar matematika siswa kelas XI IPA SMA Negeri 1 Kuripan tahun pelajaran 2019/2020. Jenis penelitian yang digunakan adalah quasi eksperimen. Penentuan sampel menggunakan teknik sampling jenuh dengan memilih seluruh populasi sebagai sampel, yaitu kelas XI IPA. Instrumen penelitian berupa angket motivasi, kecemasan dan kesadaran metakognisi dengan terlebih dulu dilakukan uji validitas dan reliabilitas di kelas XII IPA 1 dan XII IPA 2. Sebelum analisis regresi linier sederhana dan uji-t dilakukan, data yang telah diperoleh terlebih dulu dilakukan uji prasyarat, yaitu uji normalitas, homogenitas dan linieritas. Berdasarkan hasil analisis data dengan menggunakan statistik inferensial, diperoleh hasil bahwa terdapat pengaruh positif motivasi belajar matematika terhadap kesadaran metakognisi, motivasi belajar matematika terhadap hasil belajar matematika siswa, dan kesadaran metakognisi terhadap hasil belajar matematika siswa, serta terdapat pengaruh negatif $(r=$ -0,065) kecemasan belajar matematika terhadap hasil belajar matematika siswa.
\end{abstract}

Kata Kunci: Motivasi; Kecemasan; Kesadaran Metakognisi; Hasil Belajar Matematika Siswa 


\section{Cara Mengutip}

Wicaksana, M.W.J., Baidowi, Kurniawan, E., \& Turmuzi, M. (2021). Pengaruh motivasi dan kecemasan belajar matematika terhadap kesadaran metakognisi dan kaitannya dengan hasil belajar matematika. Griya Journal of Mathematics Education and Application, 1(1), 81-89.

\section{PENDAHULUAN}

Permendiknas No. 22 Tahun 2006 menyatakan bahwa matematika merupakan ilmu universal yang mendasari perkembangan teknologi dan memajukan daya pikir manusia untuk menciptakan teknologi di masa depan (Depdiknas, 2006). Hal ini berarti matematika adalah hal yang perlu dipelajari sejak sekolah dasar untuk membekali siswa dengan kemampuan berpikir logis, kritis, dan kreatif. Namun kenyataannya, kemampuan matematika siswa Indonesia masih dalam tingkat rendah, yaitu hanya mampu menyelesaikan soal matematika sederhana berdasarkan TIMSS (Prastyo, Hendri, 2020). Atas penilaian TIMSS ini, Indonesia sebagai negara berkembang seyogyanya mengupakan beberapa hal agar prestasi siswa Indoneisa di dunia internasional memiliki prestasi yang baik dari segi nilai dan pengatahuan siswa Indonesia (Hadi, Syamsul; Novaliyosi, 2019).

Sejalan dengan hal tersebut, matematika juga dipandang sebagai hal yang menakutkan karena merupakan materi yang menurut siswa sulit dipahami. Hal ini dilihat saat pelaksanaan PPL di SMAN 1 Kuripan, bahwa siswa terlihat tidak aktif selama pembelajaran matematika. Saat siswa diminta untuk mengerjakan soal, beberapa siswa terlihat bingung walau sebelumnya telah diberikan contoh soal. Begitu juga saat siswa diberikan permasalahan matematika yang sedikit berbeda, siswa mulai cemas karena tidak mampu mengerjakan sendiri. Kecemasan tersebut terlihat saat siswa merasa gelisah dan takut ketika guru menunjuk seorang siswa untuk mengerjakan. Ketakutan tersebut menyebabkan siswa menjadi susah berkonsentrasi. Konsentrasi yang terganggu, membuat siswa tidak dapat mengikuti proses pembelajaran dengan baik dan menganggap materi matematika sulit.

Siswa yang memiliki intelegensi rendah dan tidak tertarik terhadap matematika, ditambah lagi dengan ketakutannya saat pelajaran matematika akan berdampak pada tidak adanya motivasi belajar siswa. Kurangnya motivasi dan adanya rasa cemas saat pembelajaran, mengakibatkan proses pembelajaran siswa menjadi terhambat sehingga saat akan dilakukan tes atau ulangan, rata-rata siswa mendapat nilai kurang memuaskan. Hal ini dilihat sesuai rata-rata hasil UAS semester genap kelas X IPA SMAN 1 Kuripan TP 2018/2019 pada tabel berikut.

Tabel 1. Rata-rata nilai UAS semester genap kelas X IPA

\begin{tabular}{cccccc}
\hline No & Kelas & Jumlah Siswa & $\begin{array}{c}\text { Nilai Rata- } \\
\text { Rata }\end{array}$ & KKM & $\begin{array}{c}\text { Ketuntasan } \\
\text { Klasikal }\end{array}$ \\
\hline 1. & X IPA 1 & 25 & 45 & 75 & $0 \%$ \\
2. & X IPA 2 & 25 & 41,2 & 75 & $0 \%$ \\
3. & X IPA 3 & 24 & 45,083 & 75 & $0 \%$ \\
\hline
\end{tabular}

Motivasi belajar itu sendiri adalah seluruh daya penggerak di dalam diri siswa yang menimbulkan kegiatan belajar agar tujuan yang dikehendaki dapat tercapai (Sardiman, 2016). Dengan suasana kelas yang kondusif tentunya membangkitkan motivasi siswa untuk belajar. Kelas yang kondusif berati guru menerapkan strategi yang dapat menarik perhatian siswa, serta tidak membuat siswa merasa takut dan cemas. Adapun 
kecemasan itu adalah perasaan tidak menyenangkan, yang ditandai dengan istilah seperti kekhawatiran, keprihatinan, dan rasa takut (Indiyani, Novita Eka; Listiara, Anita, 2006).

Berdasarkan uraian tersebut, motivasi dan kecemasan merupakan faktor internal yang mempengaruhi proses pembelajaran. Dengan adanya motivasi dan rendahnya tingkat kecemasan, maka akan timbul kesadaran dalam diri siswa untuk belajar. Kesadaran yang dimaksud pada hal tersebut yaitu kesadaran metakognitif yang berarti kesadaran tentang proses kognitif. Metakognisi merupakan kesadaran seseorang terhadap pengetahuan berpikirnya (Chairani, Zahra, 2016). Berdasarkan uraian latar belakang, maka peneliti tertarik untuk melakukan penelitian yang bertujuan untuk mengetahui pengaruh Motivasi dan Kecemasan Belajar Matematika terhadap Kesadaran Metakognisi dan kaitannya dengan Hasil Belajar Matematika Siswa.

\section{METODE}

Jenis penelitian ini adalah penelitian ex post facto dengan desain sebagai berikut:

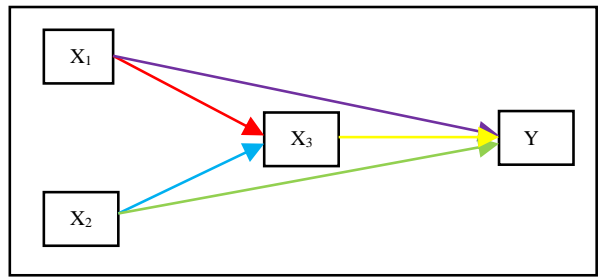

Gambar 3.1 Desain Penelitian

Keterangan:

$\mathrm{X}_{1}$ : Motivasi Belajar Matematika

$\mathrm{X}_{2}$ : Kecemasan Belajar Matematika

$\mathrm{X}_{3}$ : Kesadaran Metakognisi

Y : Hasil Belajar Matematika

Sumber: (Sugiyono, 2012)

Populasi dalam penelian ini adalah seluruh siswa kelas XI IPA SMAN 1 Kuripan yang terdiri dari 3 kelas sebanyak 74 siswa. Teknik sampling yang digunakan yaitu sampling jenuh. Sampel yang dipilih adalah seluruh kelas XI IPA. Teknik pengumpulan data yang digunakan adalah angket dan dokumentasi. Dokumentasi berfungsi untuk mengumpulkan data berupa dokumen hasil nilai UAS Semester Ganjil Tahun Pelajaran 2019/2020. Sedangkan, angket untuk mengumpulkan data motivasi, kecemasan dan kesadaran metakognisi. Dalam mengukur instrumen, skala yang digunakan adalah skala Likert. Pengujian validitas isi dapat dibantu dengan kisi-kisi dan berdasarkan pendapat ahli. Adapun untuk validitas butir soal ditentukan dengan rumus korelasi Product Moment. Sedangkan, teknik yang digunakan untuk menentukan reliabilitas adalah dengan rumus Kuder-Richardson.

Teknik analisis data yang digunakan adalah analisis regresi linier sederhana. Sebelum melakukan analisis regresi, terlebih dahulu dilakukan uji asumsi, yaitu uji normalitas, uji homogenitas dan uji linieritas. Uji normalitas dihitung dengan menggunakan rumus Chi-Kuadrat. Uji homogenitas dilakukan dengan uji Bartlett. Sedangkan, uji linieritas digunakan rumus uji F. Analisis regresi linear sederhana digunakan untuk mengetahui bentuk pengaruh variabel bebas terhadap variabel terikat. Persamaan umumnya adalah $Y=a+b X$. Adapun untuk menguji hipotesis tentang pengaruh secara parsial masingmasing variabel, maka digunakan uji-t dengan rumus: $t_{\text {hitung }}=\frac{r \sqrt{n-2}}{\sqrt{1-r^{2}}}$. Kriteria yang 
digunakan dalam mengambil keputusan yaitu $H_{0}$ ditolak jika $t_{\text {hitung }}>t_{\text {tabel }}$ atau nilai sig yang diperoleh $<0,05$.

\section{HASIL DAN PEMBAHASAN}

\subsection{Hasil Uji Instrumen}

Berdasarkan uji validitas isi dari komentar dan saran validator, diperoleh bahwa instrumen motivasi, kecemasan dan kesadaran metakognisi berkriteria sangat valid. Selanjutnya uji validitas empiris (uji validitas butir soal) yang dilakukan di kelas XII IPA-1 dan XII IPA-2 sebanyak 47 siswa di SMAN 1 Kuripan. Diperoleh hasil bahwa instrumen motivasi belajar, kecemasan belajar dan kesadaran metakognisi telah memenuhi kriteria kevalidan dan layak digunakan. Sementara dari hasil Uji Reliabilitas instrumen diperoleh bahwa Uji Reliabilitas Motivasi Belajar Matematika dari 20 item pertanyaan diperoleh Cronbach's Alpha 0,712; sementara Uji Reliabilitas Kecemasan Belajar Matematika dari 25 item pertanyaan diperoleh Cronbach's Alpha sebesar 0,901; dan Hasil Uji Reliabilitas Kesadaran Metakognisi dari 52 item diperoleh Cronbach's Alpha sebesar 0,926.

\subsection{Hasil Uji Asumsi}

Berdasarkan hasil uji Normalitas data diperoleh signifikansi data motivasi sebesar 0,200; signifikasi data kecemasan sebesar 0,063; signifikansi data metakognisi sebesar 0,200; dan signifikansi nilai data sebesar 0,200. Uji normalitas yang digunakan adalah Kolmogorov-Smirnov. Dengan membandingkan nilai sig yang diperoleh dengan 5\%, maka diperoleh kesimpulan bahwa nilai dari angket motivasi, kecemasan, kesadaran metakogisi dan hasil belajar berdistribusi normal.

Selanjutnya uji homogenitas varians menggunakan levene statistic diperoleh signifikansi data motivasi sebesar 0,896; signifikansi data kecemasan sebesar 0,472; signifikansi data metakognisi sebesar 0,589; dan data nilai sebesar 0,026. Dengan membandingkan nilai sig yang diperoleh dengan 5\%, maka disimpulkan bahwa nilai angket motivasi, kecemasan belajar dan kesadaran metakogisi berdistribusi homogen. Sedangkan untuk nilai hasil belajar tidak berdistribusi homogen, karena nilai sig yang diperoleh 0,026< 0,05 .

Terakhir berdasarkan uji linieritas, diperoleh bahwa Motivasi Belajar Matematika $\left(\mathrm{X}_{1}\right)$ dengan Kesadaran Metakognisi $\left(\mathrm{X}_{3}\right)$, memiliki nilai $F$ hitung $<F$ tabel, yakni $0,568<$ 1,835 dan signifikasi sebesar 0,930, maka dapat dikatakan bahwa bentuk regresi adalah linier; Kecemasan Belajar Matematika $\left(\mathrm{X}_{2}\right)$ dengan Kesadaran Metakognisi $\left(\mathrm{X}_{3}\right)$, memiliki nilai $F$ hitung $<F$ tabel, yakni 0,623 $<1,863$ dan signifikasi sebesar 0,899, maka dapat dikatakan bahwa bentuk regresi adalah linier; Motivasi Belajar Matematika $\left(\mathrm{X}_{1}\right)$ dengan Hasil Belajar Matematika (Y), memiliki nilai $F$ hitung $<F$ tabel, yakni 1,594< 1,835 dan signifikasi sebesar 0,103, maka dapat dikatakan bahwa bentuk regresi adalah linier; Kecemasan Belajar Matematika $\left(\mathrm{X}_{2}\right)$ dengan Hasil Belajar Matematika (Y), memiliki nilai $F$ hitung $<F$ tabel, yakni 0,713 $<1,863$ dan signifikasi sebesar 0,820, maka dapat dikatakan bahwa bentuk regresi adalah linier; dan Kesadaran Metakognisi $\left(\mathrm{X}_{3}\right)$ dengan Hasil Belajar Matematika (Y), memiliki nilai $F$ hitung $<F$ tabel, yakni 0,816 < 1,949 dan signifikasi sebesar 0,715, maka dapat dikatakan bahwa bentuk regresi adalah linier.

\subsection{Hasil Analisis Statistik Inferensial}

Berdasarkan uji hipotesis yang dilakukan untuk mengetahui pengaruh variabel bebas terhadap variabel terikat diperoleh bahwa: Uji Hipotesis Pertama, diperoleh nilai 
$t_{\text {hitung }}>t_{\text {tabel }}$, yakni 3,468 $>1,671$ yang berarti $\mathrm{H}_{0}$ ditolak; Uji Hipotesis Kedua, diperoleh nilai $t_{\text {hitung }}<t_{\text {tabel }}$, yakni 0,730 $>1$,671 yang berarti $\mathrm{H}_{0}$ diterima; Uji Hipotesis Ketiga, diperoleh nilai $t_{\text {hitung }}>t_{\text {tabel }}$, yakni 12,193 $>1,671$ yang berarti $\mathrm{H}_{0}$ ditolak. Dalam hal ini, untuk mencari nilai $t_{\text {hitung }}$ digunakan rumus Separated Varians, dikarenakan nilai hasil belajar matematika yang diperoleh tidak berdistribusi homogeny; Uji Hipotesis Keempat, diperoleh nilai $t_{\text {hitung }}>t_{\text {tabel }}$, yakni 13,783 $>1,671$ yang berarti $\mathrm{H}_{0}$ ditolak. Dalam hal ini, untuk mencari nilai thitung digunakan rumus Separated Varians; dan Uji Hipotesis Kelima, diperoleh nilai $t_{\text {hitung }}>t_{\text {tabel }}$, yakni 34,808 $>1,671$ yang berarti $\mathrm{H}_{0}$ ditolak. Dalam hal ini, untuk mencari nilai thitung digunakan rumus Separated Varians.

Selanjutnya dari analisis Regresi Linier Sederhana, diperoleh Persamaan Regresi Linier Sederhana untuk variabel motivasi dan metakognisi, yakni $Y=83,868+0,879 x$; variabel motivasi dengan hasil belajar, yakni $Y=-18,966+0,837 x$; variabel kecemasan dan hasil belajar, yakni $Y=49,276-0,108 x$; dan variabel metakognisi dan hasil belajar, yakni $Y=$ $-1,532+0,289 x$.

\subsection{Pembahasan}

Hari pertama, dilaksanakan pada 22 November 2019 di kelas XI IPA-1 dan XI IPA-2. Hari kedua dilaksanakan pada 27 November 2019 dikelas XI IPA-3, dimana setiap kelas diberikan angket penelitian yang harus diisi. Adapun jumlah siswa yang hadir mengisi angket penelitian ini adalah 61 orang. Selanjutnya, hari ketiga yang dilaksanakan pada 6 Desember 2019 untuk memperoleh nilai UAS Ganjil Tahun Pelajaran 2019. Nilai diperoleh dari guru matematika peminatan kelas XI IPA.

\subsubsection{Pengaruh Motivasi Belajar Matematika terhadap Kesadaran Metakognisi}

Berdasarkan hasil analisis data untuk mengetahui pengaruh motivasi belajar matematika terhadap kesadaran metakognisi menggunakan SPSS digambarkan melalui tabel berikut.

Tabel 3.1 Perhitungan Parsial SPSS Hipotesis Pertama

\begin{tabular}{llrrrrr}
\hline \multirow{2}{*}{ Model } & \multicolumn{2}{c}{$\begin{array}{l}\text { Unstandardized } \\
\text { Coefficients }\end{array}$} & \multicolumn{2}{c}{$\begin{array}{c}\text { Standardized } \\
\text { Coefficients }\end{array}$} & T & Sig. \\
\cline { 2 - 7 } & \multicolumn{2}{c}{ B } & Std. Error & Beta & & \\
\hline \multirow{2}{*}{1 (Constant) } & 83.868 & 18.221 & & 4.603 & .000 \\
\cline { 2 - 7 } & Motivasi (X) & .879 & .253 & .412 & 3.468 & .001 \\
\hline
\end{tabular}

Pada tabel 3.1, diketahui $t_{\text {hitung }}$ sebesar 3,468. Karena $t_{\text {hitung }}>t_{\text {tabel }}$ yaitu 3,468 $>1,672$, maka $H_{0}$ ditolak. Bentuk persamaan regresinya yaitu $Y=83,868+0.879 X$. Sehingga dapat disimpulkan terdapat pengaruh positif motivasi belajar matematika terhadap kesadaran metakognisi siswa dengan koefisien korelasi sebesar 0,412. Hal ini sejalan dengan penelitian sebelumnya yaitu penelitian (Nurani, Mawar, 2017) yang menyimpulkan, motivasi belajar berpengaruh langsung secara signifikan terhadap kesadaran metakognisi siswa dengan koefisien korelasi 0,310 pada siswa kelas VIII SMP Negeri 3 Sungguminasa. Sesuai dengan teori yaitu, kesadaran metakognisi yang mempengaruhi prestasi sebenarnya bergantung kepada pola motivasi seorang siswa (Masrura, Sitti Inayah, 2013). Ini berarti siswa-siswa kelas XI IPA SMAN 1 Kuripan yang memiliki motivasi belajar matematika yang tinggi juga memiliki kesadaran yang tinggi pula dalam belajar dan menyelesaikan tugas matematika, atau yang disebut dengan kesadaran metakognisi, begitu juga sebaliknya. 


\subsubsection{Pengaruh Kecemasan Belajar Matematika terhadap Kesadaran Metakognisi}

Tabel 3.2 Perhitungan Parsial SPSS Hipotesis Kedua

\begin{tabular}{|c|c|c|c|c|c|c|}
\hline \multirow{2}{*}{\multicolumn{2}{|c|}{ Model }} & \multicolumn{2}{|c|}{$\begin{array}{l}\text { Unstandardized } \\
\text { Coefficients }\end{array}$} & \multirow{2}{*}{$\begin{array}{c}\begin{array}{c}\text { Standardized } \\
\text { Coefficients }\end{array} \\
\text { Beta }\end{array}$} & \multirow[t]{2}{*}{$\mathrm{T}$} & \multirow[t]{2}{*}{ Sig. } \\
\hline & & B & $\begin{array}{c}\text { Std. } \\
\text { Error }\end{array}$ & & & \\
\hline \multirow{2}{*}{1} & (Constant) & 136.200 & 14.555 & & 9.358 & .000 \\
\hline & Kecemasan (X) & .135 & .185 & .095 & .730 & .468 \\
\hline
\end{tabular}

Setelah melakukan analisis data, berdasarkan tabel 3.2 diketahui $t_{\text {hitung }}$ sebesar 0,730. Adapun nilai $t_{\text {hitung }}<t_{\text {tabel }}$ yaitu $0,730<1,672$, maka $H_{0}$ diterima. Ini berarti, tidak terdapat pengaruh kecemasan belajar matematika terhadap kesadaran metakognisi siswa. Hal ini tidak sesuai dengan teori yang ada yaitu, kecemasan dapat mempengaruhi proses kognisi siswa selama proses belajar. Pendapat tersebut berarti bahwa semakin rendah tingkat kecemasan siswa, maka tingkat kesadaran untuk belajar dan mengerjakan tugas matematika semakin tinggi. Namun, setelah dilakukan analisis perhitungan, ternyata kecemasan belajar matematika siswa justru tidak berpengaruh terhadap kesadaran metakognisi siswa. Sejalan dengan penelitian (Nurani, Mawar, 2017) yang menyimpulkan bahwa kecemasan matematika tidak berpengaruh secara langsung terhadap kesadaran metakognisi siswa SMP Negeri 3 Sungguminasa.

\subsubsection{Pengaruh Motivasi Belajar Matematika terhadap Hasil Belajar Matematika}

Tabel 3.3 Perhitungan Parsial SPSS Hipotesis Ketiga

\begin{tabular}{llrrrr}
\hline \multirow{2}{*}{ Model } & \multicolumn{2}{c}{ Unstandardized Coefficients } & \multicolumn{2}{c}{$\begin{array}{c}\text { Standardized } \\
\text { Coefficients }\end{array}$} \\
\cline { 2 - 6 } & & \multicolumn{1}{c}{ B } & Std. Error & Beta & \\
\hline \multirow{2}{*}{1} & (Constant) & -18.966 & 21.805 & & .338 \\
\cline { 2 - 5 } & Motivasi (X) & .837 & .303 & & .303 \\
\hline
\end{tabular}

Dengan menggunakan rumus uji-t Separated Varians, diketahui $t_{\text {hitung }}$ sebesar 12,193 dengan nilai $r$ sebesar 0,338. Karena koefisien regresi $(b)$ mempunyai nilai positif dan $t_{\text {hitung }}>t_{\text {tabel }}$ yaitu 12,193 $>1,672$, maka $H_{0}$ ditolak. Bentuk persamaan regresinya yaitu $Y=-18,966+0.837 X$. Sehingga disimpulkan terdapat pengaruh positif motivasi belajar matematika terhadap hasil belajar matematika siswa dengan koefisien korelasi sebesar 0,338 . Hal ini tidak sejalan dengan penelitian sebelumnya yaitu penelitian (Nurani, Mawar, 2017) yang menyimpulkan, motivasi belajar tidak berpengaruh langsung terhadap hasil belajar matematika siswa pada siswa kelas VIII SMP Negeri 3 Sungguminasa. Padahal, sesuai dengan teori yang ada yaitu adanya motivasi dalam diri siswa, akan lebih bisa mengatasi kesulitan-kesulitan dalam belajar dan sebagai pendorong siswa untuk mencapai hasil belajar yang maksimal (Novalinda, Eri; Kantun, Sri; Widodo, Joko, 2017). Semakin sering siswa mempelajari materi dan soa-soal matematika, maka akan semakin terbiasa pula siswa tersebut menjawab soal. 


\subsubsection{Pengaruh Kecemasan Belajar terhadap Hasil Belajar Matematika Siswa}

Tabel 3.4 Perhitungan Parsial SPSS Hipotesis Keempat

\begin{tabular}{|c|c|c|c|}
\hline \multirow{2}{*}{ Model } & Unstandal & Coefficients & Standardized Coefficients \\
\hline & $\mathrm{B}$ & Std. Error & Beta \\
\hline \multirow{2}{*}{$1 \frac{(\text { Constant })}{\text { Kecemasan }(\mathrm{X})}$} & 49.276 & 16.908 & \\
\hline & -.108 & .215 & -0.065 \\
\hline
\end{tabular}

Berdasarkan lampiran, dapat diketahui $t_{\text {hitung }}$ sebesar 13,783 dengan nilai $\mathrm{r}$ sebesar $-0,065$. Karena koefisien regresi mempunyai nilai negatif dan $t_{\text {hitung }}>t_{\text {tabel }}$ yaitu $13,783>1,672$, maka $H_{0}$ ditolak. Bentuk persamaan regresinya yaitu $Y=49,276-$ $0,108 X$. Sehingga dapat disimpulkan bahwa terdapat pengaruh negatif kecemasan belajar matematika terhadap hasil belajar matematika siswa dengan koefisien korelasi sebesar 0,065. Hal ini tidak sejalan dengan penelitian (Nurani, Mawar, 2017) yang menyimpulkan kecemasan belajar matematika tidak berpengaruh langsung terhadap hasil belajar matematika siswa SMP Negeri 3 Sungguminasa.

Pada umumnya siswa mengalami kecemasan ketika dihadapkan pada pelajaran yang dianggap sulit, atau guru tegas dalam mengajar serta siswa cemas ketika menghadapi ujian (Solihah, Frinda Imroatus, 2017). Dengan adanya kecemasan inilah siswa merasa menjadi tidak fokus selama pembelajaran matematika berlangsung. Ketidakfokusan siswa dalam belajar malah nantinya akan berdampak negatif terhadap hasil belajar, dimana hasil belajar yang diperoleh tidak sesuai yang diharapkan.

\subsubsection{Pengaruh Kesadaran Metakognisi terhadap Hasil Belajar Matematika Siswa}

Tabel 3.5 Perhitungan Parsial SPSS Hipotesis Kelima

\begin{tabular}{llrrr}
\hline \multirow{2}{*}{ Model } & \multicolumn{2}{c}{ Unstandardized Coefficients } & $\begin{array}{c}\text { Standardized } \\
\text { Coefficients }\end{array}$ \\
\cline { 2 - 5 } & \multicolumn{1}{c}{ B } & Std. Error & Beta \\
\hline \multirow{2}{*}{1} & (Constant) & -1.532 & 21.564 & \\
\cline { 2 - 5 } & Metakognisi (X) & .289 & .146 & .250 \\
\hline
\end{tabular}

Berdasarkan tabel di atas, dapat diketahui $t_{\text {hitung }}$ sebesar 34,808 dengan nilai $r$ sebesar 0,250 . Karena koefisien regresi (b) mempunyai nilai positif dan nilai $t_{\text {hitung }}>t_{\text {tabel }}$ yaitu $34,808>1,672$, maka $H_{0}$ ditolak. Bentuk persamaan regresinya yaitu $Y=-1,532+$ $0,289 X$. Sehingga dapat disimpulkan terdapat pengaruh positif kesadaran metakognisi siswa terhadap hasil belajar matematika siswa dengan koefisien korelasi sebesar 0,250.

Hal ini tidak sejalan dengan penelitian sebelumnya yaitu penelitian (Nurani, Mawar, 2017) yang menyimpulkan, bahwa kesadaran metakognisi tidak berpengaruh langsung terhadap hasil belajar matematika siswa pada siswa kelas VIII SMP Negeri 3 Sungguminasa. Padahal, sesuai dengan teori yang ada yaitu kemampuan metakognisi dan prestasi akademik memiliki hubungan positif yang dapatdiberdayakan (Pratiwi, Indri; Suratno; Iqbal, Moch, 2016). Hubungan yang positif dimaksud bahwa, semakin tinggi kesadaran siswa akan pengetahuan kognitifnya, maka akan mempengaruhi hasil belajar yang semakin tinggi pula.

\section{PENUTUP}

Berdasarkan hasil penelitian dan pembahasan, diperoleh kesimpulan bahwa Motivasi belajar matematika berpengaruh positif terhadap kesadaran metakognisi siswa kelas XI 
IPA SMA Negeri 1 Kuripan Tahun Pelajaran 2019/2020; Kecemasan belajar matematika tidak berpengaruh terhadap kesadaran metakognisi siswa kelas XI IPA SMA Negeri 1 Kuripan Tahun Pelajaran 2019/2020; Motivasi belajar matematika berpengaruh positif terhadap hasil belajar matematika siswa kelas XI IPA SMA Negeri 1 Kuripan Tahun Pelajaran 2019/2020; Kecemasan belajar matematika berpengaruh negatif terhadap hasil belajar matematika siswa kelas XI IPA SMA Negeri 1 Kuripan Tahun Pelajaran 2019/2020; Kesadaran metakognisi siswa berpengaruh positif terhadap hasil belajar matematika siswa kelas XI IPA SMA Negeri 1 Kuripan Tahun Pelajaran 2019/2020.

\section{UCAPAN TERIMA KASIH}

Penulis mengucapkan terimakasih kepada bapak Drs. Baidowi, M.Si dan Eka Kurniawan, S.Pd., M.Pd selaku pembimbing dalam penulisan skripsi, yang sekaligus memberi arahan untuk menulis kembali hasil penelitian ini dalam dalam bentuk artikel jurnal. Semoga artikel jurnal ini dapat bermanfaat bagi semuanya.

\section{REKOMENDASI}

Dalam kegiatan belajar mengajar pentingnya guru memperhatikan faktor yang mempengaruhi hasil belajar, serta mengelola dan membantu siswa dalam mengurangi tingkat kecemasan siswa dengan tujuan agar siswa dapat memperoleh nilai hasil belajar matematika yang baik. Serta pentingnya mengatur alokasi waktu penelitian, agar faktorfaktor lain yang dapat mempengaruhi kesadaran metakognisi dan hasil belajar matematika siswa dapat teridentifikasi dengan baik.

\section{REFERENSI}

Chairani, Zahra. (2016). Metakognisi Siswa dalam Pemecahan Masalah Matematika. Yogyakarta: CV Budi Utama.

Depdiknas. (2006). Permendiknas Nomor 22 Tahun 2006 Tentang Standar Isi Sekolah Menengah Atas. Jakarta: Depdiknas.

Hadi, Syamsul; Novaliyosi. (2019). TIMSS Indonesia (Trends in International Mathematics and Science Study). Prosiding Seminar Nasional \& Call For Papers, Program Studi Magister Pendidikan Matematika Universitas Siliwangi , 562 - 569.

Indiyani, Novita Eka; Listiara, Anita. (2006). Efektivitas Metode Pembelajaran Gotong Royong (Cooperative Learning) Untuk Menurunkan Kecemasan Siswa Dalam Menghadapi Pelajaran Matematika (Suatu studi Eksperimental pada Siswa di SMP 26 Semarang). Jurnal Psikologi Universitas Diponegoro , 3 (1), 10 -28.

Masrura, Sitti Inayah. (2013). Faktor-faktor Psikologis yang Mempengaruhi Kesadaran Metakognisi dan Kaitannya dengan Prestasi Belajar Matematika. JURNAL MATEMATIKA DAN PEMBELAJARAN (MAPAN) , 1 (1), 1 - 18.

Novalinda, Eri; Kantun, Sri; Widodo, Joko. (2017). Pengaruh Motivasi Belajar Terhadap Hasil Belajar Mata Pelajaran Akuntansi Siswa Kelas X Jurusan Akuntansi Semester Ganjil SMK PGRI 5 Jember Tahun Pelajaran 2016/2017. Jurnal Pendidikan Ekonomi: Jurnal Ilmiah Ilmu Pendidikan, Ilmu Ekonomi, dan Ilmu Sosial , 11 (2), 115- 119.

Nurani, Mawar. (2017). Pengaruh Motivasi Belajar dan Kecemasan Matematika Terhadap Kesadaran Metakognisi dan kaitannya dengan hasil belajar Matematika Siswa Kelas VIII di SMP Negeri 3 Sungguminasa pada materi Bangun Ruang Sisi Datar. Makassar: Skripsi Pendidikan Matematika FMIPA Universitas Negeri Makassar.

Prastyo, Hendri. (2020). Kemampuan Matematika Siswa Indonesia Berdasarkan TIMSS. Jurnal Padegogik , 3 (2), 111 - 117.

Pratiwi, Indri; Suratno; Iqbal, Moch. (2016). Peningkatan Kemampuan Metakognisi dan Hasil Belajar Siswa dengan Pendekatan Keterampilan Proses Melalui Think Pair Share pada 
Siswa Kelas X-3 SMAN Yosowilangun Lumajang Tahun 2014/2015. Jurnal EdukasiURNAL EDUKA Unej , 3 (2), 22 - 28.

Sardiman. (2016). Interaksi \& Motivasi Belajar Mengajar. Jakarta: Grafindo Persada.

Solihah, Frinda Imroatus. (2017). Pengaruh Tingkat Kecemasan Siswa Terhadap Prestasi Belajar Sejarah Siswa Kelas X IPS 2 SMAN 12 Surabaya. AVATARA, e-Journal Pendidikan Sejarah, 1138 - 1150.

Sugiyono. (2012). Metode Penelitian Kuantitatif, Kualitatif dan R\&D. Bandung: Alfabeta. 